\title{
The Bias Paradox: Are Standpoint Epistemologies Self-contradictory?
}

\author{
Tobias Engqvist \\ Stockholm University, Sweden \\ Email: tobias.engqvist@philosophy.su.se
}

(Received 9 August 2019; revised 2 April 2020; accepted 20 April 2020; first published online 1 July 2020)

\begin{abstract}
Standpoint epistemologies are based on two central theses: the situated knowledge thesis and the thesis of epistemic privilege. The bias paradox suggests that there is a tension between these two notions, in the sense that they are self-contradictory. In this paper, I aim to defend standpoint epistemologies from this challenge. This defense is based on a distinction between subjective and objective justifications. According to the former, a subject $\mathrm{S}$ is subjectively justified in believing a proposition $\mathrm{P}$ iff S's belief in $\mathrm{P}$ coheres with S's pre-existing beliefs. According to the latter, a subject $S$ is objectively justified in believing a proposition $\mathrm{P}$ iff S's subjective justification is truth-conducive. I argue that, if the situated knowledge thesis is spelled out in terms of subjective justification, and if the thesis of epistemic privilege is spelled out in terms of objective justification, then there is no contradiction. If this line of thought is correct, then the bias paradox does not show that standpoint epistemologies are self-contradictory.
\end{abstract}

Keywords: standpoint epistemology; bias paradox; subjective; objective; justification

\section{Introduction}

In recent years, standpoint theories have arguably not been given their due attention (outside of feminist epistemology, that is). I think that this needs to change. This is due to the fact that they might offer an interesting approach for tackling questions concerning phenomena like knowledge resistance, which has seen an increase in interest due to the debate on fake news in the years following Brexit and the election of President Trump. This very application, though, will not be argued for here. Instead I will focus on an argument which targets the coherence of the theories themselves.

Standpoint theories can be said to be grounded on two central notions, the situated knowledge thesis and the thesis of epistemic privilege. According to the former, knowledge is always local in the sense that it is always relative to the knower's cultural and political - that is social - circumstances. The latter, in turn, claims that some, often marginalized, social positions - or standpoints - are less partial and less distorted than others, and thereby they are more likely to generate more knowledge (Rolin 2006: 125; Crasnow 2014: 147-8).

(C) The Author(s), 2020. Published by Cambridge University Press. This is an Open Access article, distributed under the terms of the Creative Commons Attribution-NonCommercial-NoDerivatives licence (http://creativecommons.org/ licenses/by-nc-nd/4.0/), which permits non-commercial re-use, distribution, and reproduction in any medium, provided the original work is unaltered and is properly cited. The written permission of Cambridge University Press must be obtained for commercial re-use or in order to create a derivative work. 
Rolin (2006) argues that there is a tension between these two notions. The situated knowledge thesis suggests that all knowledge is partial, but the thesis of epistemic privilege seems to challenge this very idea by suggesting that some standpoints are superior to others (Rolin 2006: 126). Standpoint theories are thus said to be undermined by an inherent self-contradiction, what Rolin and others refer to as a bias paradox. In this paper, I will argue against this claim.

Section 1.1 will be used to define and clarify some basic expressions and notions that will recur throughout the paper. In $\$ 2$, I will illuminate the different, and unfortunately often quite loosely defined, components that are the core of standpoint theories in general. This is done mainly in order to offer some clarifications regarding the interpretations of the general notions that I aim to defend, but also to give an account for the theories in question. I will then, in $\$ 3$, defend standpoint theories from the challenge posed by the bias paradox. My defense is based on a distinction between subjective and objective justifications, inspired by Alston's (1988) internalist externalism. I claim that subjective justification is gained when a belief coheres with other, pre-existing, beliefs, and that objective justification is gained when one's subjective justifications are truth-conducive. With help from this distinction, I argue that the paradox can be resolved and that it is thus merely apparent. In the fourth and final section I will argue for my conclusion and my main thesis, that the bias paradox does not show that standpoint theories are self-contradictory.

\subsection{Definitions and clarifications}

When speaking about knowledge, I am referring to propositional knowledge of the kind 'S knows that P'. 'Knowledge' itself is supposed to be understood in accordance with the traditional notion as justified true belief. ${ }^{1}$ Justifications, truths and beliefs will in turn be referred to as 'aspects of knowledge'. Things or circumstances about which we can know will be referred to as 'objects of knowledge', while 'knower' refers to human beings with the capacity of knowing. Now, several writers have challenged this kind of individualistic understanding of knowledge, ${ }^{2}$ but since the defense of epistemic individualism is not the aim of this paper, I will not discuss these challenges at length here. Instead, I will rest my case on the assumption that the claim that some kind of collective or community is necessary for knowledge simply is too strong to make. As support for this train of thought, I ask the reader to picture yourself stranded on a desolate island, where you are the sole human being. Somehow, you have never encountered or even heard of the local fauna or flora before. Surely, if you study these beings, then you will be able to learn about them and their behavior - you will be able to gain knowledge even if there are no other people around. Of course, you might sometimes get things wrong. If some other person arrived, they might see some things differently, and thereby you might be able to learn from each other. But this does not suggest that you cannot learn anything at all by your own lights, which consequently supports the idea that knowledge de facto is reducible to individuals. More can obviously be said about this topic, but I will not cover it further at this time.

The term 'standpoint theory' often refers to 'feminist standpoint theory'. Here, 'standpoint theories' will instead be used as an umbrella term. In this wider sense, it includes not only the feminist understanding, but also other versions such as the Marxist interpretation. 'Standpoint theory' should thus, if not stated otherwise, be understood in general terms that includes several different versions of the theory.

\footnotetext{
${ }^{1}$ The debate about Gettier problems will be excluded in this context.

${ }^{2}$ See e.g. Code (2014) and Longino (2002a, 2002b).
} 
The examples provided throughout the paper should therefore not be understood as implicit acceptances of specific theories, but rather as illustrative clarifications of certain notions. Here, I will not try to decide which specific interpretation of standpoint theory is the correct one, but instead focus on the question of whether it is reasonable to accept the conjunction of the general notions of the theories or not. 'Standpoint theory' and 'standpoint epistemology' will be used interchangeably.

Lastly, I think it is important to point out that this paper exclusively concerns knowledge rather than truth. I assume that there is a reality which exists independently of us, and that it is this reality that determines the truth value of propositions. No argument will be given for this assumption. Instead, I will focus on my main objective, which is to deal with questions about how we interpret said reality, and what make some group's interpretations better than other group's interpretations.

More definitions and clarifications will be provided throughout the paper.

\section{On standpoint theories}

Standpoint theory has its roots in Marxist traditions. According to Cohen (2013), Marx would argue that:

[T] he situation of the proletariat has unique features which ensure that its intellectual representative is developing a theory which is not an ideology, that he is possessed of a correct rather than an illuded consciousness of reality. The position of the workers is such that they have a privileged access to the facts about reality in general and society in particular. (Cohen 2013: 271, emphasis mine)

Nowadays though, the theory is often associated with feminism. Harding (2015) writes:

The standpoint accounts propose that in order to obtain more objective accounts of nature and social relations, researchers should start research from outside the dominant conceptual frameworks - namely in the daily lives of oppressed groups such as women. (Harding 2015: 30, emphasis mine)

With that in mind, standpoint epistemologies can be described as involving the following two concepts; situated knowledge and epistemic privilege. These concepts will be explicated in $\$ 2.1$ and $\$ 2.2$. I will then, in $\$ 2.3$, address and clarify how 'standpoint' is to be understood. Finally, in $\$ 2.4$, I will specify how I interpret said notions.

\subsection{The situated knowledge thesis}

The central notion of the situated knowledge thesis is that all knowledge is local. That is, knowledge is relative to one's social circumstances. What one is able to know is determined by cultural and political factors, and some people will therefore have access to knowledge that is unavailable to others. According to standpoint theory then, there is no "view from nowhere" from which one can bypass one's social filter and thereby obtain an unaffected view of reality (Heikes 2004: 321; Crasnow 2014: 147; Harding 2015: 43). 'Situated knowledge' can be defined as follows:

Situated knowledge: Knowledge that is dependent on social factors.

Thus, if all knowledge is situated, then all knowledge is such that it is dependent on social factors. 


\subsection{The thesis of epistemic privilege}

The situated knowledge thesis is closely connected to the thesis of epistemic privilege. This is a conceptualization of the idea that if the situated knowledge thesis is true - if different people have access to different knowledge by virtue of their social circumstances - then this will result in some people having more knowledge than others, since they are able to know things that others cannot (Rolin 2006: 125; Crasnow 2014: 148).

The problem is to determine exactly who holds this privilege. Given what has been stated earlier, the main take away is that historically it has been claimed that those who are not inside "the box of normality" - those who are not part of the leading class or of the dominant social group etc. - are the ones who will have a less distorted view of reality (more on this in the next paragraph). To illustrate this idea, consider the following: We often see prosperous white middle-aged males in leadership positions, as leading actors in popular culture, etc. The white middle-aged male is the ideal, and much of society is built to suit his needs; he embodies "normality". Now, it is not a stretch to imagine, at least in many cases, that such a person will have a harder time grasping concepts that lie outside "the box of normality" than a person who, knowingly, exists in the outskirts of society. And since the ideal of the white male is prominent throughout society, the outsider (or the oppressed) will not only have access to his or her own experiences, but also to - at least - some of the same knowledge as the white middle-aged male (knowledge which can be seen as being embedded within the social framework). Of course, there might be some outsiders who, for one reason or another, do not see things this clearly, but ceteris paribus it is certainly plausible to claim that the outsider by virtue of consciously being part of "the oppressed" - has an epistemic privilege relative to the white middle-aged male.

With what has been stated above in mind, 'epistemic privilege' can be defined like this:

Epistemic privilege: If a subject A (in social circumstance c) is able to know proposition $\mathrm{p}$ and if a subject B (in social circumstance c') is not able to know p, then A has epistemic privilege regarding $\mathrm{p}$.

As with standpoint theories, I will not try to decide exactly who de facto holds epistemic privilege, but instead focus on the question of whether there are any reasons for accepting the notion or not.

\subsection{On standpoints}

In order to truly understand standpoint epistemology, it is often argued that one must make a distinction between a standpoint and a perspective. This distinction can be made a little clearer by the following four claims, made by Harding (2004: 31-2):

(1) From a standpoint it is possible to see through the way in which dominant groups or institutions create and maintain oppressive social relations.

(2) The abovementioned is done by locating different forms of social and material disadvantage.

(3) Oppressed perspectives are not automatically privileged.

(4) Standpoints are not directly ascribed to individuals, but rather focus on creating groups' consciousnesses.

I want to point out that what has been stated above does not necessarily align with $m y$ view of a standpoint. I, for one, hold the belief that it is possible that some non- 
marginalized standpoints could hold epistemic privilege in certain domains. But since Harding's account is rather well-accepted and quite widespread, and mainly because my aim here simply is to show that standpoint theories in general are not self-contradictory, this debate will not be expanded upon at this time.

A standpoint, as delineated above by Harding, can be contrasted with perspective in two ways: First, from a standpoint it is possible to see through ideologies, but from a perspective it is not. Second, a distinction needs to be made through the way they are formed. In contrast to a perspective, which is something that each individual naturally has, a standpoint is actively achieved through hardship. It is an oppressed group's consciousness of reality, created by political struggle against its oppressor, and the idea seems to be that an individual can achieve a standpoint through the understanding that he or she is a part of an oppressed group. This is to be contrasted with the oppressors who mainly - and more than often unknowingly - form their social beliefs not in the name of finding truth, but rather to maintain status quo. Hence, the oppressed are able to get a clearer picture of the way things really are (Harding 2004: 31-2).

\subsection{Areas of investigation}

With what has been stated in the preceding paragraphs in mind, a definition of 'standpoint theory' can be presented as follows:

Standpoint theory: A is able to know proposition p because A is (knowingly) in an "oppressed" social circumstance c, and B is not able to know proposition $\mathrm{p}$ because $\mathrm{B}$ is in an "advantageous" social circumstance c'.

As we can see, knowledge about proposition $\mathrm{p}$ is situated in the sense that both A and B are dependent on social factors - their social circumstances - in knowing or not knowing $\mathrm{p}$. The fact that $\mathrm{A}$ is able to know $\mathrm{p}$ also implies that A has epistemic privilege regarding $\mathrm{p}$.

Now, there are two notions that need to be further addressed. First, in the statement that " $\mathrm{A}$ is able to know proposition p because A is (knowingly) in an "oppressed" social circumstance $c$ " and "B is not able to know proposition p because B is in an "advantageous" social circumstance c', 'because' is ambiguous. It can mean both that B does not have a default causal access to certain propositions (but that B possibly can gain access in certain ways, perhaps by interacting with and learning from people who have said access), or that B is logically, i.e. constitutively, excluded from certain propositions. This distinction is suggested by Ashton and McKenna (2018). They claim that the former type of dependence affects what we are justified in believing, in the sense that our social standing affects what we are interested in and thereby also what we will choose to investigate. The latter type of dependence, on the other hand, determines the actual constitution of the evidence itself (Ashton and McKenna 2018: 4-5). Now, if one assumes that there is a reality that exists independently of us, then it appears to be quite hard to argue for the notion of constitutive dependence. Because if the very constitution of 'evidence', rather than our beliefs on the matter, would somehow change with one's social standing, then that would imply that reality itself would somehow change. In other words, if evidence would be constitutively dependent on social factors, then the assumption that there is a world that exists independently of us would be impossible to make. Another reading suggests that women and men, people of color and white people, homosexuals and heterosexuals, rich and poor and so on would be constituted in such a way that they have fundamentally different experiences of reality. This would in turn imply that it would be impossible for people from different social circumstances to learn 
from each other. This reading does not exclude the aforementioned assumption about reality, but the claim that humans would somehow be segregated in this fundamental way certainly sounds too strong. Therefore, what will be addressed in this paper is the notion that justifications are causally dependent on social factors, and this is what 'justifications are dependent on social factors' will refer to. ${ }^{3}$ With this line of reasoning in mind, I propose a revised definition of 'situated knowledge':

\section{Situated knowledge*: Knowledge that is causally dependent on social factors.}

Second, what "A is able to know" and what " $\mathrm{B}$ is not able to know" has been stated to be determined by cultural or political, i.e. social, factors. Since knowledge is determined by the aspects of knowledge - that is true justified belief - these must be what is really affected. The question then, is which of these aspects are affected by social factors. To illustrate this, imagine the following:

Karl and Josephine are both scientists who study rhesus monkeys. Recent findings have shown that the monkeys' sexual activity increases by the time the females are ovulating, and now the two scientists, independently of each other, try to find out why this is the case. Karl assumes that the males are the ones who take action, and therefore desperately tries to find out how the male monkeys can know when the time for mating is right. He embarks on long expeditions and observes the monkeys for months without finding any proof for his hypothesis. Still, he is sure that he is right. Josephine, on the other hand, has for many years witnessed how the experiences of women and females unfairly and structurally have been excluded and repressed by the scientific community in general. Being fed up with this state of affairs, she makes the case that it actually might be the female rhesus monkeys that initiates the act, something that quickly proves to be correct. ${ }^{4}$

In this example Josephine can clearly be said to have access to knowledge about the rhesus monkeys' mating procedures. Karl on the other hand, who at least partly based his hypothesis on his beliefs about what it means to be male, didn't even consider the possibility that it was the females who initiated sex. (Feminist) standpoint theory can explain the scientists' ability or disability to access the knowledge in question; it has to do with their different standpoints - with Josephine being a woman and Karl being a man - and with Josephine being aware of her social position.

Now, their being able and not able to gain knowledge can be explained in three ways: First, the fact about the rhesus monkeys could be said to be true for Josephine but not for Karl; second, Josephine could be able to believe in the fact about rhesus monkeys but Karl could not; and third, Josephine could be justified in believing the fact about rhesus monkeys but Karl could not be. These possibilities are elucidated by Table 1 (where (p) stands for "female rhesus monkeys initiate mating").

As mentioned in $\$ 1.1$, the first row, which depicts truth as being relative to one's circumstances, can be ruled out. This is because I have already assumed that there is a reality which exists independently of us, and that it is this reality that determines the truth value of propositions. Hence, if my assumption is correct, truth cannot be

\footnotetext{
${ }^{3}$ Please note that not all standpoint theorists endorse this reading of social dependence. Even so, this is what I consider to be the most plausible interpretation.

${ }^{4}$ This example is inspired by a real-life case (Ashton and McKenna 2018: 10).
} 
Table 1.

\begin{tabular}{lcc}
\hline & $\begin{array}{c}\text { Josephine, as a woman } \\
\text { (i.e. A in circumstance c) }\end{array}$ & $\begin{array}{c}\text { Karl, as a man } \\
\text { (i.e. B in circumstance c') }\end{array}$ \\
\hline Truth & $\mathrm{p}$ & $\sim \mathrm{p}$ \\
\hline Belief & Belief in $\mathrm{p}$ & $\sim$ Belief in $\mathrm{p}$ \\
\hline Justification & Justified belief in $\mathrm{p}$ & $\sim$ Justified belief in $\mathrm{p}$ \\
\hline
\end{tabular}

relative to one's circumstances. This leaves beliefs and justifications as the only aspects of knowledge which can be affected by social factors. These aspects of knowledge will be examined closer in the next section, when we charge head-on into the bias paradox.

\section{The bias paradox}

The Bias Paradox in Feminist Standpoint Epistemology ${ }^{5}$ is described by Rolin (2006) in an article with the same name. ${ }^{6}$ The paradox, it is suggested, emerges due to the fact that the thesis of epistemic privilege seems to contradict the thesis of situated knowledge. If all knowledge is situated, it is claimed, then one cannot objectively decide that some standpoints are "less partial and less distorted" than others (as in some standpoints having epistemic privilege) and vice versa (Rolin 2006: 125-6). Put differently, the two notions seem to exclude each other.

The bias paradox can be reconstructed as follows:

P1. All knowledge is situated. (EP)

P2. Some standpoints are "less partial and less distorted" than others. (EP)

P3. If (P2), then all knowledge is not situated. (IP)

C1. All knowledge is not situated. (P2, P3)

C2. All knowledge is situated and all knowledge is not situated. (P1, C1)

It can also be understood like this:

$\mathrm{P} 1^{*}$. All knowledge is situated. (EP)

$\mathrm{P} 2^{\star}$. Some standpoints are "less partial and less distorted" than others. (EP)

$\mathrm{P}^{*}$. If (P1), then one cannot know that some standpoints are "less partial and less distorted" than others. (IP)

$\mathrm{C} 1^{\star}$. One cannot know that some standpoints are "less partial and less distorted" than others. $\left(\mathrm{P}^{\star}, \mathrm{P} 3^{\star}\right)$

$\mathrm{C} 2^{\star}$. Some standpoints are "less partial and less distorted" than others and one cannot know that some standpoints are "less partial and less distorted" than others. $\left(\mathrm{P} 2{ }^{\star}, \mathrm{C}^{*}\right)$

Regarding the second reconstruction, it must be emphasized that the conclusion $\left(\mathrm{C} 2^{\star}\right)$ is not, strictly speaking, a contradiction. But it nonetheless sounds perplexing to claim that some standpoints are "less partial and less distorted" than others if one cannot possibly

\footnotetext{
${ }^{5}$ Since the argument also applies to standpoint theory in general, I will be using the previously introduced umbrella term going forward.

${ }^{6}$ The bias paradox was originally presented by Anthony (1993).
} 
know this very claim. Consequently, it is reasonable to say that even though the reconstruction in question does not support the claim that standpoint theories are inherently contradictory, it still suggests that they are contradictory in practice.

The reconstructions above show valid derivations - both conclusions follow deductively from their respective premises - with the first one concluding in a reductio ad absurdum.

As we can see above, the bias paradox emerges because it highlights what appears to be implicit premises ( $\mathrm{P} 3$ and $\mathrm{P}^{*}$ ), which in turn makes the conjunction of the theories' premises false in the sense that they lead to contradictory conclusions. Therefore, if the reconstruction of the bias paradox is correct, then standpoint theories are de facto selfcontradictory. In $\$ 3.3$, I will show that the contradictory conclusions seen above actually rest on a false acceptance of $(\mathrm{P} 3)$ and $\left(\mathrm{P} 3^{\star}\right)$. If these premises cannot be accepted, then neither can the paradox be.

Rolin claims that the apparent paradoxical nature of standpoint theories can be explained by acknowledging that the epistemic privilege thesis seems to rely on an assumption that there is some kind of "standard of impartiality". She writes that "in order to argue that some socially grounded perspectives are better than others, a standpoint epistemologist would have to be able to identify privileged perspectives from a noninterested position, but according to standpoint epistemology, there is no such position" (Rolin 2006: 126, emphasis mine).

In order to tackle the paradox, Rolin argues for a contextualist notion of justification; the default and challenge model, which is claimed to not imply the "standard of impartiality" that is mentioned above. This view, though, is accused of being relativistic, and Rolin tries to defend the theory from this objection by drawing a distinction between the default and challenge model and so-called framework-relativism (which can be understood, roughly, as "everything goes"). The default and challenge model is said to presume that if one's beliefs are challenged, then one must either defend said beliefs or change them - something that is not true for framework-relativism. This ensures that Rolin's approach is properly sensitive to criticism in a way that framework-relativism is not (Rolin 2006: 127-30). The problem, though, is that this understanding of 'justification' can be claimed to lack a proper connection to reality. Differently put, whether one is justified in one's beliefs or not seems to be wholly dependent on one's perceived context and the epistemic challenges at hand, which in turns leaves a gap between one's justification and the world outside of these factors.

Now, my aim here is not to repudiate contextualism, hence I will not dwell upon the aforementioned. Instead, I will argue that there is another way to demonstrate that no "standard of impartiality" is needed to prove that some socially grounded perspectives are able to produce more knowledge than others. This is done in order to remove the crutch of having to rely on contextualism in order to solve the problem at hand.

In 2004, the bias paradox was examined by Heikes. ${ }^{7}$ She suggests that rationality must have both a priori and a posteriori dimensions: "[R]ationality requires the ability to form beliefs according to certain standards, but it further requires that one form these beliefs so that one can make decisions and perform actions that respond to the world around one" (Heikes 2004: 331). The idea behind this

\footnotetext{
${ }^{7}$ Heikes suggests that the paradox is a problem not only for feminist epistemologies, but that it is relevant for all epistemic theories which abandon pure objectivity in favor of accounts which somehow incorporate biases (Heikes 2004: 315).
} 
quote is, in short, that rationality and reasoning contain both subjective and objective aspects, and this claim is in turn said to form the basis of a possible solution to the paradox - a solution which Heikes never fully developed (Heikes 2004: 32932). What I will argue for in the forthcoming paragraphs is closely related to that suggested above. As mentioned earlier, though, my account differs from Heikes' in the sense that instead of focusing on rationality - which Heike herself admits is very hard to properly pin down ${ }^{8}-$ it centers around some central aspects of knowledge themselves - beliefs and justifications. More precisely, I will show how a distinction between subjective and objective justifications can be used to loosen the grip of the bias paradox.

\subsection{Subjective justifications as beliefs}

To fully grasp the following line of reasoning, one must first understand the distinction between internalism and externalism. According to internalism, for something to count as a justification it must be internally accessible for the knower. That is, the knower must have personal grounding for his or her beliefs. Externalism, on the other hand, does not demand this. Instead, knowledge is seen as a relation between a knower and a fact, which implies that the justificatory element can exist outside of the knower (Nagel 2014: 61). Here, I will argue that both internal and external elements are required for knowledge.

In $\$ 2.4$, I stated that beliefs and justifications were the only aspects of knowledge that could be affected by social factors. In this section I will argue that, from the subjective, or internal, point of view of the knower, these two are pretty much two sides of the same coin.

From the point of view of a knower, a belief can only be justified through other beliefs or through experiences. Beliefs and experiences are, in practice, simply our only available options. But it sounds strange to say that an experience in itself can be thought of as a justification. This is because actual experiences are not stored in our brains, but rather our interpretations and memories are. In other words, our beliefs about said experiences are what is really stored. Now, it is debatable whether we have epistemic access to our emotions or not. Probably it can be said that we can have a direct epistemic access to our emotions in the moment of affection (that is, when we actually experience them). In hindsight though, it seems more reasonable to talk about it as us having beliefs about our prior emotions. Based on what has been stated above, from the point of view of the knower, justifications can be nothing but beliefs - beliefs that are generally caused by our experiences. This train of thought implies that all we truly have epistemic access to, as individual knowers, are personal beliefs. Therefore, if all of our justifications are beliefs, and if our beliefs are generally caused by our experiences, then the question of whether we think of ourselves as justified or not in believing a proposition $\mathrm{p}$ must itself be answered with reference to beliefs caused by said experiences. With this in mind, I will stipulate the following definition of 'subjective justification':

Subjective justification: Iff subject S's belief in proposition $\mathrm{p}$ coheres with S's preexisting beliefs, then $S$ is subjectively justified in believing $\mathrm{p}$.

\footnotetext{
${ }^{8}$ Heikes explicitly states that " $\left.\mathrm{t}\right]$ here are no necessary and sufficient conditions for what it means to be rational” (Heikes 2004: 330). If this is true, then 'rationality' is bordering to being undefinable.
} 
In other words, my idea of subjective justification is a kind of coherentism, which essentially is the idea that a belief is justified if it "fits" with one's personal "web of beliefs" (Williams 2001: 117). ${ }^{9}$

An objection might be aimed at the idea that subjective justifications are beliefs, generally caused by our individual experiences. This objection suggests that analytical truths - that is "truths that hold by definition or in virtue of meaning" (Williams 2001: 89) - are constituted in such a way that knowledge about them can be accessed without experiential justification. A classic example would be the proposition 'all bachelors are unmarried males'. This proposition can be assessed without the empirical process of investigating whether it is true or not, because the truth of the proposition is embedded within the very notions it expresses. Therefore, some might claim, the belief that 'all bachelors are unmarried males' is not caused by any individual experience, and thus this knowledge is not situated. This objection though, misses the fact that in order to be justified in believing the proposition, one must first have access to the relevant notions. If all one has ever experienced is a social circumstance where marriage is nonexistent, then it would be impossible for that person to know that 'all bachelors are unmarried males'. This shows that analytical knowledge is dependent on social factors - that it is situated.

Now, if all we as individual knowers can ever epistemically rely on is our own beliefs, then what each and every one of us count as evidence for a certain proposition must certainly co-vary with our experiences, which in turn are affected by social factors. Thus, the notion of subjective justification seems to explain the situated knowledge thesis. To clarify this claim, imagine the following:

Henry and Magnus have completely different backgrounds. Henry, a person of color in his forties, was raised by a nearly broke single parent in a worn-down neighborhood. From childhood and beyond, he has been forced to endure many struggles. He fought to get through school, which barely had any educated teachers (those with an education preferred to work in finer districts, where they got better wages). His mother had to work two jobs in order to keep a roof over their head and did not have any time to help him with his homework. Today, Henry cleans the floors at 'Huge Enterprise Inc.' (HEI).

Magnus, on the other hand, is a white man who was brought up in a wealthy neighborhood. His mom and dad were both high-income earners, so they were able to send Magnus to a well-respected private school. All in all, he has never had to worry about anything in his life. Today he is 37 years old and holds an important position at HEI.

During a company survey, they both get asked whether skin color affects one's chance to become CEO at HEI. Magnus, who knows almost everyone at the

\footnotetext{
${ }^{9} \mathrm{An}$ interesting side note of what has been stated here is that, since our beliefs (and thereby also our subjective justifications) are generally caused by our experiences of reality - which has been assumed to exist independently of us - reality itself must somewhat limit what we are able to believe. It may be possible that we reach different conclusions based on our interpretations, but these conclusions cannot be just about anything. Furthermore, this also suggests that it is possible that we all, despite our different social circumstances, can reach the same conclusion regarding some objects of knowledge. These could be, for example, logical and mathematical principles, or maybe things that are often considered basic descriptions (like the fact that there is a certain set of trees in a certain forest, or whether it rains in a certain place at a certain time). But, crucially, we would still be dependent on our pre-existing beliefs to be able to justify these new beliefs. Much can be said about this, but although it is certainly an interesting topic, it will not be expanded further here.
} 
company and is certain that none of them would deny a person of color a fair chance to advance up the corporate ladder, almost instinctively answers " $n$, skin color does not affect one's chance to become CEO at HEI". Henry, on the other hand, has personally experienced the hardships that many people of color have to face as they grow up. Based on his belief that many of these people will not have access to a proper education, he answers "yes, skin color does affect one's chance to become CEO at HEI".

This example clearly shows what I mean with being subjectively justified. Both Henry's and Magnus' beliefs - that skin color does or does not affect one's chance to become CEO at HEI - coheres with their pre-existing beliefs. Therefore, both Henry and Magnus are subjectively justified in their respective beliefs.

It might be objected that the cause of Henry's and Magnus' different answers can be found in their interpretations of the question, and that the example above therefore in no way implies that they should somehow have different access to the relevant knowledge. This is indeed a relevant objection, but I will stay away from responding just yet, and instead return to this matter in the next section.

By now, it may be evident that the fact that a knower is subjectively justified in believing a certain proposition $\mathrm{p}$ does not entail that $\mathrm{p}$ is de facto true. But if this is the case, then standpoint epistemologies seem to be inevitably collapsing into some kind of inherently incoherent epistemic relativism. Because if all we as individual knowers can ever have epistemic access to is our own individual beliefs, then it appears that it would be impossible for us to be justified outside of our own web of beliefs. This would in turn imply that two knowers could be justified in believing fully contradictory propositions, without any way to determine that one of them must be right in his or her belief, while the other must be wrong. They would simply both be right, relative to their respective web of beliefs. In this sense, one could even say that subjective justifications would imply that no one could ever be able to truly know anything at all. In the following section, I will argue that this threat can be avoided by acknowledging that there is also an objective side to justifications.

\subsection{On the objectivity of justifications}

In order to explicate objective justifications, I will turn to Alston's (1988) internalist externalism. Alston writes that "to be justified in believing that $\mathrm{p}$ is for that belief to be based on an adequate ground" (Alston 1988: 265, emphasis mine). His argument rests on the distinction between grounding and adequacy. The grounds themselves are claimed to be internalist, because they are thought of as internally accessible psychological states of a subject - as beliefs about subject matters - rather than external facts (Alston 1988: 270, 274). The adequacy of a grounding, on the other hand, is instead said to be externalist. This is because the adequacy of one's grounds is determined by their truth-conduciveness. Alston claims that "the ground must be such that the probability of the belief's being true, given that ground, is very high" (Alston 1988: 269). In other words, if a knower's grounding properly correlates with reality, then the knower's grounding is truth-conducive and thus also adequate. The external dimension of adequacy can be highlighted by the fact that Alston claims that the knower does not need to be aware of whether his or her grounds are adequate or not. In other words, adequacy is an external matter of fact (Alston 1988: 274).

Alston's idea of internal grounding seems to fit well with my understanding of subjective justification, and with inspiration from his notion of external truth- 
conduciveness. ${ }^{10}$ I will hence stipulate the following definition of 'objective justification':

Objective justification: Iff subject S's belief in proposition $\mathrm{p}$ is subjectively justified, and if that subjective justification is truth-conducive, then $S$ is objectively justified in believing $\mathrm{p}$.

The definition of objective justification shows that a truth-conducive subjective justification results in objective justification. And if justification indeed contains some external, objective, elements - that is, if it is possible for us to be justified not just within our web of beliefs, but also on external grounds - then that prevents the notion from collapsing into inherently incoherent epistemic relativism as implied by subjective justification.

Now, let us see how the application of the notion of objective justification affects the case with Henry and Magnus from the previous paragraph. Magnus is, as stated earlier, subjectively justified in his belief about skin color at HEI, but he is not objectively justified. This because his subjective justification - the belief that his co-workers will not deny a person of color a fair chance - is not truth-conducive. In this case, even if Magnus' belief about his co-workers is true, one's skin color is still likely to affect one's chances to become CEO in some other, more indirect, manner (namely through the possibility to acquire a proper education).

Henry, on the other hand, is both subjectively and objectively justified in his belief about skin color. His subjective justification - that many people of color will not have access to proper education - is truth-conducive. Those who do not have a proper education will not stand a chance in the race up the corporate ladder, and thereby their chance to become CEO is drastically diminished.

In the previous section, it was suggested that the cause of Henry's and Magnus' different answers could be found in their respective interpretations of the original question, rather than them having different access to the knowledge in question. To this, one may reply that their interpretation of the question actually is a crucial part of the answer to why Henry and Magnus can be said to have different access to the knowledge at hand. Since Magnus has lived a sheltered life, he does not think beyond the walls of HEI, and thus he does not even consider that there could be other reasons explaining why skin color could affect one's chance to become CEO at HEI. Therefore, he interprets the question the way he does - that is, in the only way he can. Henry, on the other hand, is situated in such a way that his social circumstances enable him to consider more relevant parameters, and thus his answer is justified by a belief that tends to align with the way things really are.

In order to clarify why purely external justification is not sufficient for knowledge, let us now also consider the following:

Cornelia has a rare talent indeed. Just by looking at the exterior of a company building, she is somehow able to determine whether skin color affects one's chance to become $\mathrm{CEO}$ at that very company. At this particular day, she makes her firsttime visit to the country in which Henry and Magnus live - a country about which she does not have any prior knowledge. Here, she just happens to stroll by HEI - a

\footnotetext{
${ }^{10}$ For the sake of transparency it should be noted that Alston is a self-proclaimed reliabilist - i.e. a pure externalist. He argues that a "mere reliable belief production ... is sufficient for knowledge" (Alston 1988: 281). I instead claim that justification is de facto necessary for knowledge.
} 
company about which she also has no prior knowledge - and correctly states - as in believes - that skin color does affect one's chance to become CEO at HEI. ${ }^{11}$

Cornelia's case can be interpreted in two ways; either Cornelia is not aware of her abilities or she is aware of them. If she is not aware of her abilities, then she cannot be subjectively justified in her belief about skin color at HEI. That is because if she does not believe that she has the abilities in question, then she does not have anything to base her belief about skin color on. Even a pure externalist would have a hard time explaining this situation, because if Cornelia de facto has said abilities, then the fact that she is not aware of them surely implies that her belief about skin color at HEI can be nothing but a belief simpliciter. Now, if Cornelia is aware of her abilities, then her belief about skin color at HEI must surely be based on her pre-existing beliefs about her abilities. Ergo, if Cornelia is aware of her abilities, then she is subjectively justified in her beliefs about skin color at HEI, and since this subjective justification is truth-conducive, she must also be objectively justified in said belief.

In the preceding sections, I have showed that social factors play an important role when a knower forms his or her beliefs - beliefs which then are used to subjectively justify further beliefs. I then showed that truth-conducive subjective justifications result in objective justifications. If my analysis is correct, then objective justifications - a kind of hybrid theory of justification, containing both internal and external elements - seem to be that which is referred to when one speaks about 'justification' as being an aspect of knowledge. But it must be emphasized that, if a subject $S$ lacks subjective justification for $S$ 's belief in proposition $p$, then it is also impossible for $S$ to be objectively justified in believing $\mathrm{p}$. Thus, subjective justifications are necessary but not sufficient for objective justifications, and truth-conducive subjective justifications are both necessary and sufficient for objective justification. In the following section, I will show how the distinction dissolves the bias paradox.

\subsection{The paradox revisited}

The situated knowledge thesis can be spelled out in terms of subjective justification. According to this idea, what $S$ subjectively can be justified to believe is wholly determined by S's pre-existing beliefs, which in turn are determined by S's experiences - i.e. social factors. In this sense, knowledge is surely local as implied by the situated knowledge thesis.

Conversely, the epistemic privilege thesis can be spelled out in terms of objective justification. Recall the original example with Henry and Magnus - the notion of subjective justification implies that different knowers can be justified in holding different beliefs:

A is subjectively justified in believing $\mathrm{P}$ in circumstance $\mathrm{c}$, and $\mathrm{B}$ is subjectively justified in believing $\sim \mathrm{P}$ in circumstance $c^{\prime}$.

If we apply the notion of objective justification - that $S$ is objectively justified if S'S subjective justification is truth-conducive - and assume that A's subjective justification is truth-conducive, then the following should be clear:

A is objectively justified in believing $\mathrm{P}$ in circumstance $\mathrm{c}$, and $\mathrm{B}$ is not objectively justified in believing $\sim \mathrm{P}$ in circumstance $c^{\prime}$.

\footnotetext{
${ }^{11}$ This example is inspired by a similar thought experiment by BonJour (1980), where a clairvoyant is somehow able to pinpoint the exact whereabouts of the US president.
} 
Earlier, while presenting the reconstruction of the bias paradox, I mentioned that it highlights what appear to be implicit premises ( $\mathrm{P} 3$ and $\left.\mathrm{P} 3^{\star}\right)$, which in turn make the conjunction of the theories' premises false. These premises $-(\mathrm{P} 3)$ and $\left(\mathrm{P} 3^{\star}\right)-$ suggested the following:

P3: If some standpoints are "less partial and less distorted" than others, then all knowledge is not situated.

P3*: If all knowledge is situated, then one cannot know that some standpoints are "less partial and less distorted" than others.

My hybrid theory proves that one can accept neither (P3) nor (P3*). The false acceptance of $(\mathrm{P} 3)$ and $\left(\mathrm{P} 3^{*}\right)$ is caused by the crucial mistake of not seeing how the situated knowledge thesis and the thesis of epistemic privilege really relate to one another. Because if the situated knowledge thesis is true, then so is the thesis of epistemic privilege. The notion of subjective justification implies that all knowledge is situated in the sense that it is always dependent on social factors, and the notion of objective justification implies that certain subjective justifications could obtain epistemic privilege through their truth-conduciveness. Simply put, if all knowledge is such that it is dependent on social factors, then some social circumstances will be better at producing objective justifications than others, and therefore some knowers will be able to know things that other knowers will not. To think otherwise would be to claim that all possible social circumstances would produce the same objective justifications, but that would simply be a too strong claim to make. Thus, if the situated knowledge thesis is explained by the notion of subjective justification, and if the thesis of epistemic privilege can be thought of as a knower or a group of knowers in a certain social circumstance being objectively justified in believing a certain proposition $\mathrm{p}$ in virtue of their truth-conducive subjective justification, then the bias paradox is nothing but an intellectual mirage. In other words, even if all knowledge is de facto situated in the sense that our subjective justifications always are dependent on social factors, it is still possible to know that some subjective justifications tend to produce "less partial and distorted" objective justifications through their truth-conduciveness. And even if some subjective justifications tend to produce "less partial and less distorted" objective justifications through their truth-conduciveness, all knowledge is still situated in the sense that our subjective justifications - which are necessary for objective justifications - always depend on social factors. Thus, there is no contradiction. Therefore, I claim that the bias paradox does not show that standpoint theories are self-contradictory.

As previously mentioned, Rolin (2006: 126) stated that "in order to argue that some socially grounded perspectives are better than others, a standpoint epistemologist would have to be able to identify privileged perspectives from a non-interested position". My hybrid theory, which distinguishes between subjective and objective justification, has shown that no such identification is necessary to explain situated knowledge or epistemic privilege. Still, it is an entirely different thing to decide who de facto holds said privilege, but as already mentioned, that is a question for another time.

\section{Conclusion}

In this paper, I have provided a deductively strong argument for my thesis - that the bias paradox does not show that standpoint theories are self-contradictory. 
I commenced with some clarifications regarding the central notions of standpoint theories in general; the situated knowledge thesis and the thesis of epistemic privilege. In connection to these accounts, I also presented the interpretation of standpoint theories in general that I aimed to defend. This reading suggested that justification's dependence on social factors should be understood in causal terms, and that the aspects of knowledge affected by social factors are beliefs and justifications.

Thereafter, I accounted for - and reconstructed - the bias paradox. This challenge to standpoint epistemology suggests that there is a tension between the situated knowledge thesis and the thesis of epistemic privilege, in the sense that they seem to exclude each other. After a recitation of the claim that the paradox could be traced back to an assumption that the thesis of epistemic privilege rested on the notion of a "standard of impartiality", I then defended standpoint theories from the challenge posed by the bias paradox. This defense was made in three steps.

First, I showed that all we as individual knowers can have epistemic access to is our own beliefs. This, I argued, showed that whether we think of ourselves as justified or not in believing a proposition $\mathrm{p}$ must itself be beliefs based on our subjective experiences of reality. With this in mind, I stipulated that iff subject S's belief in proposition $\mathrm{p}$ is based on S's pre-existing beliefs, then $\mathrm{S}$ is subjectively justified (internally) in believing $\mathrm{p}$.

Second, with inspiration from Alston's internalist externalism, I stipulated that iff subject S's belief in proposition $\mathrm{p}$ is subjectively justified, and if that subjective justification is truth-conducive, then $S$ is objectively justified (externally) in believing $\mathrm{p}$.

Third, my hybrid theory of justification proved that no "standard of impartiality" was needed in order to explain the situated knowledge thesis or the thesis of epistemic privilege. Because if the situated knowledge thesis is spelled out in terms of subjective justification, and if the thesis of epistemic privilege can be thought of as a knower or a group of knowers in a certain social circumstance being objectively justified in believing a certain proposition $\mathrm{p}$, then there is no contradiction. With this derivation in mind, it is now plain that the bias paradox does not show that standpoint theories are self-contradictory. ${ }^{12}$

\section{References}

Alston W.P. (1988). 'An Internalist Externalism.' Synthese 74, 265-83.

Antony L.M. (1993). 'Quine as Feminist.' In L.M. Antony and C. Witt (eds), A Mind of One's Own, pp. 185-225. Boulder, CO: Westview Press.

Ashton N.A. and McKenna R. (2018). 'Situating Feminist Epistemology.' Episteme. doi: 10.1017/ epi.2018.11.

BonJour L. (1980). 'Externalist Theories of Knowledge.' Midwest Studies in Philosophy 5, 53-73. https://doi. org/10.1111/j.1475-4975.1980.tb00396.x.

Code L. (2014). 'Ignorance, Injustice and the Politics of Knowledge.' Australian Feminist Studies 29, 148-60.

Cohen G.A. (2013). 'The Workers and the Word: Why Marx Had the Right to Think He Was Right.' In J. Wolf (ed.), Lectures on the History of Moral and Political Philosophy, pp. 268-83. Princeton, NJ: Princeton University Press.

Crasnow S. (2014). 'Science, Social Science and Feminist Critiques.' In N. Cartwright and E. Montusci (eds), Philosophy of Social Science: A New Introduction, pp. 145-61. Oxford: Oxford University Press.

Heikes D. (2004). 'The Bias Paradox: Why It's Not Just for Feminists Anymore.' Synthese 138, 315-35.

\footnotetext{
${ }^{12}$ I would like to thank Niklas Olsson Yaouzis, Åsa Burman and Björn Eriksson at Stockholm University for supporting me throughout the work on this paper. I am also very grateful for Peter Goldberg's aid regarding linguistic matters. Also, many thanks to my fellow students, as well as the anonymous reviewer at Episteme, for providing me with much valuable feedback.
} 
Harding S. (2004). 'A Socially Relevant Philosophy of Science? Resources from Standpoint Theory's Controversiality.' Hypatia 19, 25-47.

Harding S. (2015). Objectivity and Diversity: Another Logic of Scientific Research. Chicago, IL: University of Chicago Press.

Longino H. (2002a). The Fate of Knowledge. Princeton, NJ: Princeton University Press.

Longino H. (2002b). 'Reply to Philip Kitcher.' Philosophy of Science 69, 573-7.

Nagel J. (2014). Knowledge: A Very Short Introduction. New York, NY: Oxford University Press.

Rolin K. (2006). 'The Bias Paradox in Feminist Standpoint Epistemology.' Episteme 3, 125-36.

Williams M. (2001). Problems of Knowledge. New York, NY: Oxford University Press.

Tobias Engqvist is working on his MA thesis in practical philosophy at Stockholm University. His main interest is epistemology (in all its different forms), but he is also curious about social ontology and normative ethics. 'The Bias Paradox' is Engqvist's first international publication.

Cite this article: Engqvist T (2022). The Bias Paradox: Are Standpoint Epistemologies Self-contradictory? Episteme 19, 231-246. https://doi.org/10.1017/epi.2020.21 